\title{
Student attitudes and the teaching and learning of race, culture and politics
}

\author{
Kathleen J. Martin \\ California Polytechnic State University, Ethnic Studies Department, San Luis Obispo, 1 Grand Ave., CA 93407, United States
}

\begin{abstract}
A B S T R A C T
Although multicultural education and teaching for and to equity and diversity often are viewed in higher education as important around the globe, the mismatch between theory and public opinion can remain a challenge when teaching the subject. This study investigates student attitudes and learning before and after completing a course in race, culture and politics at an American university in California, and data were gathered over a three-year period from 365 students. Utilizing a Confluent Education framework that integrates cognitive, affective, and psychomotor dimensions of teaching and learning, faculty structured opportunities for students to study and discuss issues, and then, examine social settings for evidence to tie cognitive study with real world experiences. Teaching and developing courses around issues of multicultural education, diversity, and issues of power that strengthen students' abilities to perceive multiple perspectives, think critically, and learn from others are made.
\end{abstract}

\author{
Keywords: \\ Multicultural Education \\ Teaching to diversity \\ Student attitudes/beliefs \\ Confluent education, and cognitive \\ and affective learning \\ Qualitative research
}

Although multicultural education and teaching for equity and diversity are often viewed in higher education as a given across American universities in the United States in particular, the "lag" or mismatch between the theory and public opinion remains of serious concern. Some scholars indicate, "This lag between practice and discourse also manifests itself via the persistence of stereotypic representations of 'others"' (Asher, 2007, p. 65) in the media, in classrooms, and American society in general. Overcoming the disparity between the theory and practice and teaching an area of study that challenges popular opinion is difficult at best. In fact Asher (2007) contends, "for all the efforts it takes to implement such a pedagogy, the rewards are few and far between" (p. 72). However, courses and topics such as these are important components of teacher education programmes, colleges of liberal arts, and many general education programmes around the world as case studies from countries such as Brazil, Cuba, Germany, Norway, South Africa, among others demonstrate (See for example Banks, 2009; Suzuki, Fishman, \& Pušina, 2007). To gain insight into these issues, this article investigates students' perceptions and attitudes after completing a course at an American university in California. Faculty who teach the course, Race, Culture and Politics (RCP), investigate its ability to help bridge the mismatch and assist students in understanding the disparity between public opinion and multicultural education, and efforts to enact the democratic

\footnotetext{
A portion of this paper was presented at the April 2007 annual meeting of the American Educational Research Association to the Confluent Education Special Interest Group.
}

principal of equality (Shor \& Pari, 2000). The course studies issues of race, ethnicity, sexuality and gender as historical processes reflected in US institutions and society, and present in social, political, educational, economic, and legal arenas.

Finding ways to address the mismatch between research implications and theory, and popular opinions and beliefs is important when teaching issues of diversity and multicultural education in the US and around the world (Banks, 2009), particularly with discourses of power. In fact, in European countries such as Italy, France, England, and Germany who have struggled with integrating the influx of immigrant populations, particularly since the fall of the Berlin Wall, these are topics of concern in the teaching of multicultural subject matters. The persistence of stereotypes, misinformation, and popular opinion within the context of politically correct dialogues in the US creates an ongoing challenge when teaching the topics as well. And, this challenge seems to recur at the beginning of each course with each new group of students. Courses often are designed to explore ideas of multiculturalism and address the struggles of diverse students with greater understanding and awareness. Yet, they have the potential to devolve into discussions of the "other" with dominant group members remaining outside and aloof from the discussion.

Another set of complicating factors in the teaching of race, culture and politics often is the divide between those with access to excellent higher education and those without. As we move into the 
twenty-first century and witness the effects of anti-affirmative action movements and court decisions such as California's Proposition 209 in the United States, the divide is growing. In combination with this, there is an increase in dominant group attitudes that indicate a more generalized belief that any inequality in the US was addressed through the Civil Rights Movement of the 1960s. This promotes and stimulates the belief that all have equal access (typically those with power in the system), while at the same time limiting access to higher education for certain groups with fewer resources and opportunities. This is something Paulo Freire (1970/2000) began to address over 50 years ago in Brazil with his well-known Pedagogy of the Oppressed. We continue to see, however, an untenable power relationship that provides more access to those with resources, and diminishing access for those without, while simultaneously promoting the idea that multiculturalism, diversity, and equality are issues already addressed and achieved.

In a recent study regarding college access in California for example, John Yun and José Moreno (2006) indicate, "schooling disadvantage is concentrated largely in schools where AfricanAmerican and Latino students are located" (p. 18); US schools that also have a disproportionate number of students from low socioeconomic (SES) families. These findings point to the increasing difficulty of re-segregation in schools since the 1980s, and an effect of the post-Brown v. the Board of Education decision (Ladson-Billings, 2004). To address this issue in the United States, the Supreme Court "affirmed the importance of racial and ethnic diversity in higher education". The ruling concluded that "it is constitutional for educational institutions to consider race and ethnicity in admissions decisions" (Moses \& Marin, 2006, p. 3). However, few universities in the US desire to pair admittance policies with any form of affirmative action since reverse discrimination lawsuits began in the 1990s, and popular beliefs, attitudes, and perceptions about equity and equality of access to education support the notion that now everyone has equal access. Yet, when Scholastic Aptitude Test (SAT) scores are correlated with family income, the continuing effects of inequity based on economic status are suggestive. According to Gregory Mantsios (2004) in 1999 the scores of over 1.3 million SAT test takers in the US "correlate strongly with family income" (p. 202), and communities such as those studied by Yun and Moreno (2006) are often overly represented by poor and lowincome families. For each additional 10-20,000 of family income, SAT test scores increase from 15 to 30 points. However, a significant number of undergraduate students believe their place in the university system is due to their "hard work" alone, and again that the topics of equity and equality have been fully considered and rectified. With these conditions and factors prevalent and the disparity between public opinion and the realities of access, efforts "to enact the democratic and equitable intent of socially responsive education" (Stringer, 1993, p. 150) are important.

Faculty designed the RCP course to study the teaching and learning processes in what they consider to be a "difficult" course through the investigation of two principal questions: first, what classroom structures facilitate the learning of these issues for students? And, second, are there materials and activities that can support students' understanding and ability to investigate the topics while simultaneously helping students reevaluate personal attitudes and beliefs?

Most faculty struggle with ways to approach the course, pose questions and ideas for discussion, and make it through ten-weeks of what some refer to as "an emotional roller coaster of a course". Faculty members endeavor to increase students' ability to recognize their own perspectives, biases and beliefs, and to increase their awareness and knowledge of perspectives different than their own. These ideas contribute to the principal objective of this study: to examine students' understanding of diverse perspectives, attitudes, personal reflections, and awareness and knowledge of the topic before and at the end of the course. Theoretical perspectives from Confluent Education (CE) provide a framework for teaching the course and for investigating student learning regarding issues of diversity and multicultural education.

\section{Theoretical perspectives}

"In Queens, I learned that as a young Black man, I was looked down upon by much of the society and was automatically thought to be a criminal based solely on the colour of my skin, my age, as well as the way I dressed" (African-American Male, Spring 2006).

Confluent Education $(C E)^{1}$, as suggested in its name, is the coming together or confluence of several philosophical orientations: phenomenology, existentialism, and humanism. More specifically it emerged from Humanistic Education and Psychology, Gestalt Psychology, and the Human Potential Movement, which suggest "programs to liberate people and to help them 'actualize their potential”' (Shapiro, 1998, p. 30) ${ }^{2}$. It also supports a belief in the coming together of cognitive, affective and psychomotor learning, one that reflects the whole student. CE has its roots in education, law and medical professions, architecture, and the work of organizations (Brown, 1996; Castillo, 1978; Shapiro, 1997, 1998). It is described as the "flowing together of the affective and cognitive elements in individual and group learning” (Brown, G., 1972/1990). This necessitates an awareness of content and process, and "means being aware of and taking responsibility for yourself in relation to your experience and your context, people you're interacting with, [and] the topic and material you're engaging in" (Brown, J.R., 1996, p. 6). At its most basic level, CE is described as a manifestation of "the Humanist Impulse" and a movement toward political liberty (Shapiro, 1998). This translates to notions of the individual not isolated from, but rather embedded in a setting or context. Judith $\mathrm{R}$. Brown (1996) elaborates on the experiential context as one in which the process is intensified through the "here-and-now" focus that emphasizes awareness of self and focuses on the connection of self to the environment and relationships with others (p. 34). Remaining in the moment, awareness of change, attention to interpersonal and intrapersonal dynamics, reflection and metacognition, and feeling and affect are important conceptions in a Confluent Education (CE) framework for teaching and learning.

Personal awareness often must be the first stage toward internalization of new values or utilization of new learning (D'EmidioCaston, 1999; Osterman \& Kottkamp, 1993). Similar to L. S. Vygotsky's theory of the act of constructing and construction, ideas and concepts are presented to the individual from the environment, felt or experienced personally, and then, through the process of theorizing, the concepts are reorganized and understood (Cole, JohnSteiner, Scribner, \& Souberman, 1978). Further, the concept of "self" can be understood as an amalgam of what emerges from a combination of the intrapersonal and interpersonal domains (Gardner, 1983). We become aware of important truths regarding the nature of relationships as rich sources of awareness and change. These

\footnotetext{
${ }^{1}$ For a more complete description and history of Confluent Education at the University of California, Santa Barbara see G. Brown, 1972/1990; J. H. Brown, 1996; J. R. Brown, 1996; Shapiro, 1997.

2 In 1987, the University of California, Santa Barbara Archives of Humanistic Psychology was created through the efforts of California State Assemblyman John Vasconcellos and George and Judith Brown. "The scope of these archives comes from a significant repository greater than Confluent Education, but Confluent Education was the connecting link of an actual University of California program" (Shapiro, 1998,p. 152).
} 
aspects frame the learning process and provide a context for integration. Faculty who teach from a CE model also align with the following principles: 1) a value orientation consistent with the Humanistic and Human Potential movements; 2) a belief in participatory democratic values and social change; and 3) an interest in reflection, self-examination and evaluation (Shapiro, 1997). These ideas provide an avenue for personal growth and a sense of connectedness that is embodied in the close interaction and sharing of feelings present in classroom settings.

Principals of teaching and learning from Confluent Education (CE) emphasize cognitive (intellectual functioning) and affective (feelings and beliefs) learning within a context of physical activities that asks students to "do a meta". Metacognition is described as a "view from a distance, a vantage point that allows a broader scope of a situation" (Brown, J. R. 1996, p. 74). A number of years ago, Jerome Bruner (1996) noted, "pedagogy is moving increasingly to the view that the [student] should be aware of her own thought processes, and that it is crucial for the pedagogical theorist and teacher alike to help her become more metacognitive-to be as aware of how she goes about her learning and thinking as she is about the subject matter she is studying" (p. 64). The learner is provided with the opportunity to consider how they are thinking as well as what they are thinking about (Bruner, 1996), and then, to couple this with how they feel about it. Feeling and affect are important for learning, particularly when coupled with selfreflection and narrative to assist students in the examination of personal attitudes and beliefs. As noted by Suzuki et al. (2007) at a meeting of The World Council of Comparative Education Societies (WCCES), these are aspects of Confluent Education (CE) considered essential to include in "how to learn/teach multi-dimensionally-the creative integration of cognitive, affective and behavioral dimensions of learning/teaching." In the teaching of Race, Culture and Politics (RCP), faculty struggle with ways to structure the course so that students are able to integrate the ideas and take a metaperspective.

According to Hackbarth (1996), "the confluence of the cognitive and affective dimensions of learning may be interpreted as a person's actions directed toward the pursuit of knowledge" (p. 30). The teacher's goal from a CE perspective is to help students achieve a balance between cognitive and affective learning, and lessons are designed to help students increase their sense of power in the process and take responsibility for their own learning (Brown, G., 1972/1990). In research in Sweden and the Institute for Human Potential, the Netherlands and the Dutch Ministry, as well as other countries, principles of Confluent Education provide a framework for investigating and studying the integration of affective, cognitive, and psychomotor learning. These areas of study may present ways for assisting students, and people more generally, in developing more effective relations in their lives-work - and studies. In this application, the relationship between the interpersonal relations and intrapersonal dimension that are so much a part of everyday life as we interact with the world around us are emphasized. The focus is on the process of the individual in interaction with the environment and seeks to encompass the social context, setting or field. Teachers who utilize a Confluent Education framework are cognizant of principles of democratic social change and instructional values that emphasize context, change, and equity as specifically an awareness of context or environment; an educational orientation toward change that benefits people and society; and an "instructional value that emphasizes social equity, consensus and collaboration in learning" (Shapiro, 1997, p. 90). When teaching this course, the persistence of stereotypes, misinformation and "popular" opinion within the context of "politically correct" dialogues remains an ongoing challenge. With this understanding of teaching RCP from a CE framework, faculty endeavor to incorporate ways to make processes explicit, accessible, teachable, and appropriate for learning, while incorporating and structuring a variety of learning opportunities for students.

\subsection{Teaching race culture and politics}

The structure of undergraduate courses in the US typically is centered on cognitive learning, while maintaining "objective" distance from feelings and subjective experience. Courses such as RCP do not fit the "objective" distance model, and, in fact, typically are viewed as solely "subjective" by students. Unlike other subjects, course readings for RCP are often perceived as the instructors' personal opinion and of little value. This may be the combined effect of perceptions of liberal arts as a soft science, students seeing less diversity at their own higher education institutions, or of media sources that "too often behave like the lapdogs of plutocracy" (Parenti, 2006, p. 60). Often, the subject engages students' personal beliefs and attitudes, and objective distance is minimal at best. Addressing issues of equity and equality in classes and utilizing the principles of democratic social change are not easily accomplished, particularly as students' affective filter jumps into high gear. If, as has been noted by other educators, "the structure of a course teaches more profoundly than its content" (Grimes, 2000, p. 83), it becomes important to pay attention to not only what we teach, but how and in what ways learning can be facilitated. Structuring opportunities to practice reflective, group, and observation skills under the guidance of experienced facilitators (Martin, Chrispeels, \& D'Emidio-Caston, 1998) are key components of CE that address these issues as they arise within classes and among students in the moment.

In courses designed to address the lives of those from subordinated and oppressed groups, emotions and emotional responses are often present and encountered, particularly from dominant group members. Lee Brown (2006) suggests, "colonization is founded on the denial of the emotions of the oppressed" (p. 2) and that students need a more holistic approach to learning that includes affective responses as integral to the process of learning. Teaching courses with heightened emotional content requires a willingness to balance cognitive learning activities with reflective practice and discussion of feelings in an atmosphere of trust. It also has been described as "risky business-especially for feminists and others already marginalized within the hierarchy of the academy. The privileging of reason and truth prevails" (Boler \& Greene, 1999, p. 109). Yet, for faculty teaching RCP, it is imperative for students to have an opportunity to articulate experiences, feelings, and ideas that are often implicit and largely unacknowledged or recognized by peers. These ideas and theoretical perspectives from Confluent Education provide the framework for the teaching and learning of RCP, and faculty use this framework to stimulate reflection and awareness of personal perceptions and attitudes.

\section{Methods}

"I felt very naive for thinking that racism, sexism and classism doesn't happen everywhere, because it does" (White Female, Winter 2006).

Grounded in qualitative methodology, this article seeks to explore and investigate the teaching of RCP through systematic inquiry into the attitudes and perceptions of students within a specific setting for better understanding (Marshall \& Rossman, 1989). In fact, the combination of qualitative research and principles of Confluent Education (CE) may provide a method for the study of differences and the expression of diversity (Martin, 1998). Qualitative research reflects an assumption that experience can 
provide an understanding of social life and the study of groups (Van Maanen, 1998), and that the context is an essential component of the researcher's description. It seeks to examine patterns of interaction, qualities and feelings, and is uniquely suited for "strategies to study people in diverse natural settings where researchers are personally involved as their own instrument in interviewing, observing, studying documents, analyzing data, and creating a narrative to present to the world" (Brown, J. R. 1996, p. 13). The guiding principles of Confluent Education emphasize the importance of understanding and appreciating differences, and of actions, feelings, and interpersonal relationships within a social context as integral components of interaction (Brown, G. 1972/1990; Brown, J. H., 1996). Therefore, as a method appropriate for the study of attitudes, beliefs and perceptions, qualitative research in combination with CE principles is appropriate for the study of teaching and learning in which beliefs, feelings and attitudes are significant learning components.

\subsection{The course}

Race, Culture and Politics (RCP) is an introductory and interdisciplinary course focused on the ways race and ethnicity are created both by historical and current processes in American society and institutions. Students and faculty direct their attention to issues of gender, diversity, equity and ethnicity, and problems facing contemporary society, especially those resulting from racism, discrimination, and cultural conflict. The course is designed to help students increase their knowledge of history and politics and the experiences of marginalized groups, as well as to increase awareness of their own power and ability to take responsibility for their learning; these are issues of concern to teachers and students around the world. Faculty work to "engage students in opportunities to learn from each another, appreciate their different life experiences and perspectives, and gain skills to work with and across differences, and actively promote inclusion and social justice" (Gurin \& Nagda, 2006, p. 23). This encourages opportunities for students to consider how they are personally thinking and feeling about the topics, as well as listening to the perspectives of others.

At the American university where this course is taught, the course fulfills a lower-division general education and a United States Cultural Pluralism (USCP) requirement for an undergraduate degree and for an introduction to multicultural education for liberal arts and teacher education students. Paula Rothenberg's (2004/ 2006) Race, class and gender in the United States is typically used as the primary text in the course. It presents research articles and essays that students often perceive as extreme examples of "white bashing" with little basis in fact even when they investigate cited sources and research. White students particularly are affronted upon reading Peggy McIntosh's well-known article, "White Privilege: Unpacking the Invisible Knapsack" (In Rothenberg, 2004, p. 188-192). A second course text, David Shipler's, The Working Poor: Invisible in America, addresses the enduring qualities of the Horatio Alger myth: "Work hard and you will succeed, if you don't succeed it is because you didn't work hard [sic]."

\subsection{Context and participants}

The site for this study is a large public university in California with a low percentage of students who receive student aid or hold a job while they attend college. The university has five principal colleges of study for students: Agriculture, Architecture, Education, Engineering, and Liberal Arts (RCP is taught in the College of Liberal Arts, Ethnic Studies Department). The course is open to all students at the university including general education students and students in the teacher training programmes. The county population surrounding the university is low density and predominantly white. The university's student population for 2006-2007 also is predominantly white (approximately 68\%) with slightly less than $12 \%$ Asian or Pacific Islander, approximately $11 \%$ Hispanic, and a very small population of African-American ( $>2 \%$ ) and American Indian $(>1 \%)$ students. These figures reflect similar percentages for the years 1992-2006 with no substantial variations. Most students are from high socio-economic families with an average family income of approximately $\$ 85,000$ per year. Finally, there are few students who are returning to school, most are under the age of twenty-two. For approximately the last ten years, three faculty members, including the author, have taught between one and three sections of RCP each quarter with an average student enrollment for each section of 34-44 students. Typically, there are a high number of first-year and final year students who enroll, with fewer enrolled mid-programme university students.

\subsection{Data sources}

Data were gathered over a three-year period from nine course sections with 365 enrolled students, and from faculty who teach the course. Table 1 presents the sections of this course taught from spring quarter 2005 through spring quarter 2007 including enrollments, number of final responses, and pre- and post-course attitude survey results.

Student data: include student assessment of group work, end-ofthe-course-observation assignment, and a pre- and post-course attitude survey. Student responses to group work during class were collected via email. All students joined a facilitation group to lead a discussion of the week's assigned reading. Students were encouraged to design activities, prepare discussion questions, and work together as a group to make joint decisions about how to lead the class in discussion. After completing the facilitation, each member of the group was instructed to email the faculty with a short assessment of how things went, what they could have done differently, and what went well.

Students also complete an end-of-the-course observation project of a social setting designed to fulfill the requirements of a final examination. This project includes: observation notes and recorded data from four 30 min observations of a social setting; a three-page paper analyzing their findings; and a personal response to the assignment and/or course on a separate sheet of paper. The three-page papers although important, are not part of the analyzed one-page responses. As indicated in Table 1 and the final responses, over 295 students completed the one-page response.

Finally, students, in five of the course sections, completed a preand post-course attitude survey on the first and last day of class (Koppelman with Goodhart, 2005). The faculty decided to use the survey as a result of preliminary data analysis collected in the previous courses as a way of corroborating findings. The inventory asks respondents to use a five-point scale ranging from strongly agree-agree to undecided to disagree-strongly disagree to rank their responses to sixty-four attitude statements and six demographic questions. Over 199 students in five sections of the course taught between fall quarter 2006 and spring quarter 2007 completed the pre-course inventory. Not all students completed the post-course attitude inventory $(N=176)$ since some students who were present on the first day did not enroll or remain in the course for the entire quarter, and others opted not to complete the survey a second time. Table 2 reports students' responses for nine of the statements. Results from the attitude surveys help to frame the discussion as a way of looking more specifically at the number of students whose responses changed from one category to another, 
Table 1

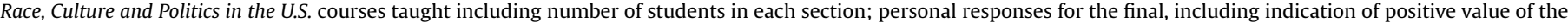
course and/or increased self-awareness at the end of the course: and attitude inventorv resbonses (pre and post).

\begin{tabular}{|c|c|c|c|c|c|c|}
\hline Quarter taught & $\begin{array}{l}\text { Enrolled students } \\
N=365\end{array}$ & $\begin{array}{l}\text { Inventory (pre) } \\
N=199\end{array}$ & $\begin{array}{l}\text { Inventory (post) } \\
N=176\end{array}$ & $\begin{array}{l}\text { Final responses } \\
N=295\end{array}$ & $\begin{array}{l}\text { Increased self-aware } \\
N=113\end{array}$ & $\begin{array}{l}\text { Positive response } \\
N=163\end{array}$ \\
\hline Spring 2007 & 36 & 38 & 28 & 29 & 12 & 20 \\
\hline Spring 2007 & 34 & 35 & 33 & 31 & 9 & 18 \\
\hline Winter 2007 & 43 & 43 & 41 & 41 & 15 & 21 \\
\hline Fall 2006 & 39 & 42 & 35 & 35 & 6 & 17 \\
\hline Fall 2006 & 41 & 41 & 40 & 41 & 19 & 21 \\
\hline Spring 2006 & 44 & ND & ND & 38 & 18 & 24 \\
\hline Winter 2006 & 39 & ND & ND & 34 & 22 & 15 \\
\hline Fall 2005 & 39 & ND & ND & 21 & 9 & 12 \\
\hline Spring 2005 & 50 & ND & ND & 25 & 3 & 15 \\
\hline
\end{tabular}

particularly in the undecided category. From this, data analysis more specifically addresses a change in attitude or belief based on the knowledge and experience students gained during the course. Although this does not speak to the students who continued to have significantly positive or negative attitudes before and after the course, it does provide the opportunity to investigate students who fall within a category that indicates an attitude change.

Faculty data: include written responses to questions regarding teaching practices related to advocacy and teaching for equity. These data were gathered from the three faculty members who routinely taught the course during the years of study. In addition, two of these faculty members acted as researchers in terms of collecting, analyzing and interpreting the data with student assistants interested in the teaching of Ethnic Studies courses.

\subsection{Data analyses}

Qualitative data sets were coded and tabulated (Miles \& Huberman, 1994), and data displays made to identify specific categories of responses by students from the final response paper. Then, they were read and reread by faculty for emerging themes and evidence of categories such as: definitions of and sense of advocacy; specific course components; relationships and interactions with others; and self-reflections. Results were compared and contrasted across data sets, and categories and units of ideas identified. Data were reexamined for new categories and ideas reflecting course perceptions, experiences, and/or increased awareness of empathy and social justice. A third level of analysis compared the attitude inventory results with emergent themes from the other student data sets. Faculty reflections on the course structure and individual sections were used to cross-reference and support categories and conclusions.

Finally, student and faculty data were independently reviewed for key themes by faculty and student researchers. Tabulations for the attitude inventory were completed, and pre- and post-course scores were compared. Bar graphs were created to display differences. An analysis of the responses was completed that grouped the statements into categories including attitudes regarding racism, educational issues, and topics of sexual orientation. Charts and data displays were made to identify trends and degrees of difference across all data sets. The next section presents some of the structure, activities, and assignments that faculty designed for the course utilizing Confluent Education principles.

\section{Perspectives and attitudes: the work of RCP}

"The most startling fact that was illuminated to me through this class is the role of government in constructing inequality and preserving inequality. I have shared some of what I learned with my friends and family. They, like many Americans, do not believe that race in America is an issue" (American Indian Female, Fall 2006).

On the first day of class, students' work in dyads or small groups designed to help them get to know each other and build trust. An activity for the first day is to read and discuss the essay Body Ritual among the Nacirema by Horace Miner (1996), a reading that presents an anthropological analysis of a group of people. The Nacirema (American spelled backwards) are presented as a "strange and savage" group of people with unusual customs (as exemplified in the cultural practices of Americans). Students read the essay and then discuss their responses, ideas and feelings in small groups. Approximately one half of the students in the classes recognize who the people are that are the subject of discussion. The other students in the class are surprised when they learn who is being discussed, but once told, they too recognize themselves in the reading. This reading provides an opening context for the discussion of stereotypes and social construction, as well as the opportunity to reflect on personal perspectives and viewpoints. Faculty members introduce students to the idea that we add meaning to readings and events from our own experiences.

Students are informed at the beginning of the course that some of the topics and materials may evoke memories and feelings as

Table 2

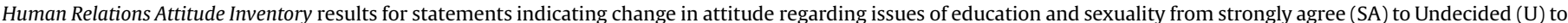
Strongly Disagree (SDA). (Pre-course responses $N=199$ and post-class responses $N=176$.)

\begin{tabular}{|c|c|c|c|c|c|c|c|c|c|c|c|}
\hline No. & Attitude Survey Statements & SA Pre & SA Post & A Pre & A Post & U Pre & U Post & DA Pre & DA Post & SDA Pre & SDA Post \\
\hline$\overline{7}$ & One's gender has very little to do with one's educational opportunity. & 34 & 11 & 65 & 59 & 28 & 18 & 54 & 66 & 17 & 19 \\
\hline 16 & Schools are biased against low-income students. & 18 & 39 & 52 & 81 & 52 & 22 & 66 & 24 & 17 & 6 \\
\hline 18 & There are many cultures in the world which accept homosexuality. & 11 & 7 & 28 & 44 & 41 & 24 & 32 & 15 & 5 & 4 \\
\hline 22 & Most psychologists no longer consider homosexuality a mental illness. & 19 & 28 & 67 & 50 & 30 & 7 & 5 & 12 & 1 & o \\
\hline 34 & Homosexuals have made many contributions ot their societies. & 15 & 20 & 37 & 57 & 29 & 13 & 19 & 5 & 7 & $\boldsymbol{0}$ \\
\hline 40 & $\begin{array}{l}\text { School textbooks and instructional materials are biased toward the middle } \\
\text { class because they omit or stereotype working class people. }\end{array}$ & 4 & 16 & 19 & 40 & 52 & 31 & 46 & 19 & 4 & 4 \\
\hline 53 & Teachers need to understand how schools perpetuate cultural racism. & 16 & 29 & 58 & 63 & 42 & 8 & 8 & 1 & 1 & 3 \\
\hline 61 & Racial segregation in our schools and neighborhoods remains a problem. & 16 & 35 & 55 & 60 & 27 & 9 & 24 & 9 & 2 & 3 \\
\hline 64 & Achievement tests discriminate against children from low-income homes. & 12 & 22 & 38 & 64 & 40 & 14 & 29 & 14 & 5 & 2 \\
\hline
\end{tabular}


they read the materials. "If you have experienced some of the actions described in the readings, they may remind you of them. If you have never experienced them and believe that they no longer exist, you may believe the text is extreme and it may anger some of you" (Faculty 1, 2007). As another faculty member noted,

A lot of our students do not want to perceive or acknowledge the reality of inequality in America. Why? Because it has not impacted them personally, they have been removed from the harsh reality and have lived in a false world or bubble. Having to confront these sensitive topics makes them very ill at ease (Faculty 2, 2007).

A discussion of Peter Senge's "Ladder of Inference" (1999) helps students begin to understand the ways humans select data that fits with personal belief systems. Sometimes students ask if the theory applies to faith-based beliefs. This is followed by a discussion of the ways we come to believe things, and then limit the amount of information that we let into our frame of reference as Senge's theory suggests. Some students respond to the first week of classes with grave doubts about the class such as: "I have conservative views and most everyone that I associate with from my home town thinks the same way that I do ... I really don't have to associate with people that are that much different than me" (White Male, Fall 2006).

During the second and third weeks of the course, activities continue to help students get to know each other and increase the level of trust in the class. Faculty lecture on the meaning of social construction (Gergen, 1999), and "the problem of difference" (Daniel Tatum, 2003), as well as show films or lead discussions on US politics and government, laws, and Supreme Court decisions. Students are asked to work on examining their perspectives and the perspectives of others through observations, data collection, and activities designed to engage them in thinking, talking, and responding to others. To facilitate this, students sit in a circle, and often break into smaller groups and dyads. "The classroom discussion is designed to elicit passionate reaction from the students: either supporting or negating the themes" and objectives of the course" (Faculty 1, 2006). A circle format helps students to face one another, and "some of our discussions make a lot of our students feel uncomfortable" (Faculty 3, 2007). In a circle, students speak more directly to one another. "This seems to help mitigate some of the dynamics of anonymous confrontation" (Faculty 2, 2007).

The third week typically presents a turning point in the discussions from students not believing in what they read, to being shocked by the appearance of discrimination. For example, the film The Angry Eye with Jane Elliot (2001) presents a simulation of what Jane Elliot calls "the live virus of racism" and the way discrimination works in real life. Jane conducts a Saturday morning exercise for college students based on eye colour: brown-eyed college students are placed in the "good group", and blue-eyed students are seated in the center of the room and treated as if they are students with limited ability. After the film, students in the RCP course are asked to write a response to two prompts: "How I felt watching the film?" And, "How do I use power?" Then, students share their responses in dyads followed by large group discussion. Most have difficulty answering the second prompt; fewer struggle with the first. Students often feel the brown-eyed students should resist and tell Jane Elliot not to "be mean" to the blue-eyed students, and they raise the issue of context, what people should do, and issues regarding position power. A discussion of the way power works in social situations often ensues. The film examines the power of explicit markers such as skin colour and gender, and tries to demonstrate that one can be internal with limited outward expression while the other cannot. The film also provides students with concrete examples of the ways racism, sexism and classism exist in the "real world". For students of colour, the film is a very real presentation of the ways white students can be privileged in classrooms. The interaction between beginning and more experienced students provides an important scaffold for learning with peers rather than faculty lecturing.

A significant number of students comment on the film in the end-of-the-quarter response seven weeks later. "One part of the class that had a huge impact on me was the video, "The Evil Eye"' (White Female, Fall 2005). Similar to other students in the class, this student did not remember the title of the film correctly, but interpreted it as "evil" instead of "angry". During the film, Jane Elliot asks Rasul, a Black student participant, "Did you know you were Black before we told you?" Students generally laugh during this point in the film because of the absurdity of the question and the realization that they too have heard or said the corresponding statement, "But I don't see you Black." White students seem to remember this statement most since it has been part of their own verbal interaction with African-American friends. Others note, "Watching The Angry Eye, I found that I tried to look at Black people not at their skin, but for who they are" (White Male, Spring 2006). Students of colour often remember it as a phrase they hear directed at them, and note the differences in reception.

I will never forget the blue eyes and brown eyes exercise that we watched. It hit home to me because those college aged children who were living such a comfortable life basically "freaked out" once they were treated unfairly and it made me realize how sheltered some people can be (Pilipino-American Female, Spring 2006).

During weeks four through nine, one class meeting each week is reserved for faculty to show a film or lecture on a relevant topic for the course. In the other weekly class meeting, student groups take turns leading the class in discussion. Students perceive the context of the class with time to hear the opinions of peers as important to their learning. And, student facilitated discussions encourage them to be creative in the presentation of course materials and increase their understanding of the course topics. In fact, student facilitators often developed learning activities that included elements of cognitive as well as affective learning, and they were pleased with their success. One student facilitator reflected: "I think people were enlightened by the information on various injustices subordinate groups in the US have faced. I left the class yesterday proud of what we were able to accomplish" (White Female, Spring 2006). Some groups have more difficulty than others. Reflecting on her group work one student noted, "I have to admit, it was quite the learning experience. If I had to do it again, I would now have a better idea for what works and what doesn't" (White Female, Fall 2006). Most students believe it to be a positive learning experience and provide thoughtful reflections on the experience and their efforts. "Our group presentation today was definitely a learning experience. ... However, the discussion could have been dealt within a different manner. It probably would have been more effective if we had passed out the responses to the class, and read them aloud" (White Female, Fall 2006).

Students' reflections in the final response indicate an increased appreciation for hearing the perspectives of others. "I think what contributed to my satisfaction and also to my knowledge were the discussion groups. My group was very diverse, and I was enthralled to hear the opinions of people with a different culture and background than myself" (White Female, Winter 2006). Students appreciated the opportunity to influence the attitudes of peers and listen to others. "I enjoyed being able to lead the class discussions with a group. Having to almost teach it, I tried to think of experiences that could help me relate to students to get the 
discussion going" (Mexican-American Female, Spring 2006). "I enjoyed the discussions because it gave everyone a chance to speak and more importantly listen to other's points of view. I think we can learn a lot from listening to others" (Mexican-American Male, Winter 2006).

During the final week of the course, students again complete the attitude survey. Some students comment that they remember the questions from the beginning of the quarter and are surprised to see that their knowledge, opinions, and answers have changed. Faculty also use this week to conclude the discussions, review any pertinent materials, and conduct a "workshop" on how to complete the final. In the "workshop", students and faculty review Senge's (1999) theory of the "ladder of inference", practice collecting social science data from the newspaper in small groups, and then discuss their findings. It is an opportunity for students to work at the level of "observable data", and practice data collection and analysis skills through an in-class exercise.

\subsection{Student reflections and the observation final}

A common response to the final reported by students is revealing. "[It] was more difficult than I expected" (White Female, Fall 2006). Students noted, "I thought this was something I didn't have to study for and it would be far more interesting than taking a test; I also assumed it would be easier for me than a midterm" (White Female, Fall 2006). And, "I had no idea how hard that task would be. To look at anything and not jump to conclusions was almost impossible" (Asian-American Male, Fall 2006). Some reported, the assignment "was a challenging one because it asked me to blend in and observe" (White Female, Fall 2006). And, "When I first heard what the final project was going to be, I thought to myself, "this should be easy"' (African-American Female, Spring 2006). "It helped to show me why social change throughout the world and especially in our country takes so long" (White Male, Spring 2006).

From the analysis of student responses to the observation assignment, two recurring themes stand out: an increased selfawareness, and the positive value of the course. First, students indicated an increase in their self-awareness and often were surprised to discover that they based many of their impressions of people on stereotypes and assumptions. Out of 295 personal responses, 113 students (over 38\%) indicated their own selfawareness increased primarily through the course and the observation assignment. One student noted, "The benefit of this exercise was going from knowing something to consciously experiencing it. Abstractly understanding that there are differences is not nearly as powerful as seeing them acted out all around you" (White Male, Winter 2006). Frequently students were surprised to "discover how many assumptions [they] make," and that they had been aware of stereotypes before the class, but only after the final observations were they aware of the extent to which pre-conceived notions influenced their own judgments of others. One student reflected, "Perhaps the most profound thing that I observed is that I am not very observant" (White Female, Spring 2007). They believed they saw the world in a new way and that social settings are very influential. "This class and assignment have shown me how unaware I was of these social interactions. They are often so subtle and have become so common that we do not question the consequences they have or the words they communicate" (Asian-American Male, Spring 2006). Another commented, "I thought that there was no way that I was going to find any real evidence of racism out on the street in today's society. I have now come to realize that I could not have been more wrong!" (White Female, Fall 2006).

The second theme revealed students' belief that the course is of crucial importance and should be a university-wide requirement, and 163 (over 55\%) of students felt it was one of the most important courses in their studies. Of the 163 responses, over 25\% acknowledged the importance of the issues presented in the class in their daily lives and interactions. Students reported, "This is the most important/worthwhile course I've taken" and "should be required for ALL students." Others commented, "After one day of observation, I could see some related issues from real life. Whenever I can see something related to real life, I am amazed" (Asian-American Male, Winter 2006). Still others reflected, "This course brings a wealth of knowledge concerning social and economic issues that we don't often see" (Asian-American Male, Spring 2007). The assignment often summed up their experience of the course.

I went into the assignment thinking, "How am I going to write a paper watching people just sit around for a few hours?" This is just how I felt coming into this class thinking, "how are my views on racism and sexism going to change in just one class?" However, little did I realize that as soon as I tried to see things from a new perspective, a whole new world opened up to me (White Male, Fall 2005).

Faculty members were surprised at the number of times these sentiments were repeated in the final responses; this was true even in classes in which a majority of students were reluctant to hear the perspectives of others or were adamant about their own perspective. Sometimes students commented, "Although this class may not have changed the lives of everyone, I can guarantee that there is at least one person who can honestly say that they look at the world in a different way and that person is me" (White Female, Spring 2007). Students were explicit about their learning and feelings about the assignment and the way it changed their perceptions. "I never had a real understanding of what people of color went through. It has helped me change the way I act around my friends and others" (White Male, Spring 2005).

A number of students concluded that this was a powerful assignment, and they were saddened by what they saw and found in their data. "The toughest part was witnessing the aloof vibes when every white group quieted down when some Black people came in [to the coffee shop]" (White Male, Winter 2006). For others, it set the tone for what they learned during the course. "For me, the assignment is not over just because the class is over" (White Female, Winter 2006).

\subsection{Faculty reflections and perspectives}

An objective for faculty teaching the RCP course is to help students become aware of their perspectives and personal attitudes, understand democratic values, achieve a balance between cognitive and affective learning, and to express their feelings as part of teaching and learning from a Confluent Education framework. During the first few weeks of class, faculty often hear comments such as, "Our generation is a colour blind society, everyone is equal and 'mixed couples' are common." Students argue, "People make too big of a deal about race". Comments often are framed as rhetorical questions. "Why do we have to re-open the old wounds associated with racism?" Or, "Women have made major strides in all facets of American society, so why are we talking about the empowerment of women at the expense of someone else?" Another common belief expressed by students is that all people are on an equal playing field, and, if you don't succeed, it is “you're own fault" as in the Horatio Alger myth. Faculty work to balance student comments and develop an atmosphere of trust so that students are able to comment openly. Sometimes this is difficult to manage. "Helping students see through the myths of meritocracy and egalitarian US society is especially challenging" (Faculty 2, 2007). 
Faculty who teach RCP believe it is a difficult course to teach, and often find it disappointing to read comments from in-class writing assignments. Students typically lack critical "comprehension of the reading and resistance to thinking in terms of racism, sexism, and issues of gender and sexual orientation can prove daunting" (Faculty 3, 2007). It is challenging because of the dual dynamic of "asking students to voice their opinions and providing a safe space during class, and second, managing the group dynamics that can arise from those opinions" (Faculty 1, 2006). "Many of the comments voiced by students from dominant groups are derogatory to marginalized groups or reflect conservative opinions that are diametrically opposed to the readings" (Faculty 1,2007$)$. Those who routinely teach this course feel they "need a break to replenish themselves because it is so demanding" (Faculty 3, 2007). To address this issue, one faculty member noted:

I tell stories to lower their affective filter: stories about growing up in surprisingly diverse Wichita, Kansas; stories about life with my blind \& autistic brother, whose 'abnormal' behavior makes him a perpetual outsider; stories about my lack of awareness of my own white/middle-class privilege, and my gradual process of acknowledging these advantages (Faculty 3, 2007).

There are a number of reasons frustrations surface for faculty when teaching this course aside from student-faculty interactions. The most difficult, as indicated by one faculty member, "Managing conflict arising from controversial issues is surely one of the most difficult demands of the class, especially when a student expresses an uninformed view that is vastly different from my own" (Faculty $1,2007)$. The single most important aspect of the work is to "create an atmosphere of trust and safety for students while maintaining a healthy dose of humor" (Faculty 3, 2007), and providing a context for "learning about RCP in the US even when your own affective filter" is engaged (Faculty 2, 2007).

\subsection{Attitude inventory}

Analysis of student responses to the pre- and post-course attitude inventory indicates changes in students' attitudes in several areas by the end of the ten-week course. Responses to nine statements are the focus of discussion. Table 2 presents the results for these statements in the areas regarding issues of race, education, sexual orientation, and poverty. Change in student responses in the "undecided" (U) category provide an interesting context for discussion regarding themes found in the other data sets. Students' responses to each of the nine statements in the undecided category diminished, sometimes significantly by the end of the course. This may reflect a change in students' knowledge of the subject after the course, enough so as to be able to make a decision about these statements, and/or a shift in attitude about the subject. Interestingly, the post-attitude survey was given prior to the final assignment; therefore, it does not include any additional insights that students might have gained from their observation investigations.

Student responses to statements 22 (Most psychologists no longer consider homosexuality a mental illness) and 34 (Homosexuals have made many contributions to their societies) are particularly suggestive of increased knowledge. At the beginning of the course 30 and 29 students respectively were undecided versus only 7 and 13 undecided by the completion of the course. Responses to statements number 53 (Teachers need to understand how schools perpetuate cultural racism) and 64 (Achievement tests discriminate against children from low income homes) also were high in the undecided category at the beginning of the course, 42 and 40 respectively. Yet, by the end of the course the number of students in the undecided category dropped dramatically to 8 and 14 respectively. Student responses to statements $22,34,53$, and 64 in the strongly agree and agree categories increased significantly in the post-course survey. For statement 53 , pre-course strongly agree and agree responses were 16 and 58 respectively, already a significant number of responses, with post-course responses 29 and 63 respectively. Responses to statement number 64 indicate the number of responses to strongly agree and agree increasing from 12 to 22 and 38 to 64 respectively. Responses to statement number 61 (Racial segregation in our schools and neighborhoods remains a problem) are interesting since the number of undecided responses dropped from 40 in the pre-course to 14 in the post-course.

For statement number 16 (Schools are biased against low-income students), students choosing to strongly agree or agree at the beginning of the course were 18 and 52 respectively, while the post-course scores were 39 and 81 respectively. Also, students who choose disagree and strongly disagree dropped from 66 to 17, and 24 to 6 respectively. This trend also was present in responses to statement number 40 (School textbooks and instructional materials are biased toward the middle class because they omit or stereotype working class people). At the start of the course 52 students marked the undecided category versus 31 at the end of the course. The next section presents the findings in relation to the $\mathrm{CE}$ framework.

\section{Discussion}

"After the first day of class, I was kind of worried. Was I going to have to sit at a desk and disagree for ten weeks? ... I turned out to be wrong. The world isn't the way I saw it to be in my small high school community" (White Female, Fall 2006).

From the beginning of the Race, Culture and Politics (RCP) course, faculty actively employed Confluent Education (CE) principles and asked students to examine personal attitudes, beliefs, and perspectives. The course structure set the tone for the class and guided students in the discovery of new perspectives from familiar contexts in combination with course materials and structured learning activities. In their final responses, students indicated the course provided a context for exploring their learning that helped to open "their eyes to racism, sexism and classism", and the preand post-course attitude responses supported these student perceptions. All students worked with a small group of peers to "teach" the class, which proved more difficult than they expected. Analysis of student responses indicated the following themes: 1) heightened awareness of the process of teaching others, and 2) increased knowledge of the issues discussed in course materials and readings. These themes reflect students' increased awareness and knowledge about the topics by the end of the course. Working in groups to present the reading material for the week helped students to closely examine the texts and prepare a discussion. They viewed this activity as critical to their development and understanding of multicultural issues in the United States, as well as an opportunity to gain insight into the process of teaching and learning from others.

The required observation final asked students to go out and look at their world. All quarter, they had been reading, listening, and studying topics that often posed perspectives different than their own. Until this time, many of the students did not believe or make the connection between what was discussed and "what is" in the world outside of the classroom. As noted by one student, experience and awareness of these issues is "below the radar of most white students" (Fall 2005). For students of colour as well as white students, the course was an "eye-opening" experience. Personal knowledge and awareness often is implicit and in need of verification from the real world. They discovered, "racism, classism and 
genderism really is happening," and their knowledge about the ways "media portrays and sometimes even provokes prejudice and stereotypes" (African-American Female, Fall 2006) increased during the course. Once they completed the final observation and reflected on the experience and the course in general, their awareness became explicit, conscious, and tied to real world experience, aspects significant from the CE framework. Now, students believed they could examine, study and reference the issues they learned about from their own experience in a social setting.

Student personal responses indicated increased awareness of the issues and objectives of the course. Some students of colour noted, "The minority must understand the system of oppression perpetuated by the majority [and] now I have a more developed understanding of it" (Guatemalan Male, Spring 2005). Other students commented on the practicality of the assignment as well as their surprise at the findings. "My initial hypothesis was completely rejected, and I realized there really is a serious issue that is prevalent in our society" (White Male, Spring 2007). Without the course, students did not believe the topics discussed in class still existed. In fact, so many students reported, "my eyes were opened" in the final response that faculty initially disregarded the answer as a "stock answer to get a grade". However, upon closer inspection of the data, student responses indicated more complexity such as: "I came into this class thinking I knew the problem, and I knew how to solve it, but to be honest, I now see how complicated racism and classism are" (White Female, Spring 2006). "I realize that now that I know what is out there, it has become part of my responsibility to help to right the wrongs our society has constructed" (White Female, Spring 2006). "I have learned that 'passivity is not an option', [and] I have told people that racist jokes are not funny" (White Female, Fall 2005). "Allies are needed to show that not all members of the dominant race are oppressors; some are here to fight discrimination" (White Male, Winter 2006). For a number of students, this new awareness led to discussions about what they were willing to do to make a difference.

Students expressed affective responses to the course, final assignment, and class discussions that indicate increased selfawareness and learning. This is important information given the design of the course that called for attention to affective responses, as well as increasing cognitive learning from a Confluent Education design. Students thought about what reflection means, struggled to identify personal perspectives, and tried to write their ideas using the first person. One student commented, "I told myself, 'I don't see colour' because it doesn't matter what colour a person is. After taking this class however, I know that it is utterly important to see colour" (White Female, Fall 2006). They asked thought provoking questions such as, "Are people too self-centered to be compassionate and care about others?" (White Female, Winter 2006). Some students commented, "It surprised me because the book at times gave extreme statements and statistics, but being able to see for myself the problems was shocking" (Mexican-American Male, Spring 2006). Many times, white students in particular expressed anger or irritation about their lack of education, and wondered why they hadn't learned this before. These were important realizations that students discovered during the final exam observations as they integrated course material with the real world.

The course structure proved fundamental for helping students deal with and discuss feelings, beliefs, and attitudes with peers. Students in the course recognized and admitted that their own assumptions often were hindering them in the study of the topic. And, the observation final helped a number of students get past the, "I don't have to believe" what I am reading stage, and move toward the "I am shocked that I didn't see it before" stage. From there, students could begin to investigate "What I can do now to act as an ally." In addition, the activities and course materials aided students in their efforts to approach the subject through the group led discussions with an active focus on listening to the perspectives of peers, and then, explore the real world for evidence. For many, they completed the course with a heightened awareness of the challenges some individuals face, as well as feeling able to make a positive contribution to society. Listening to the perspectives of peers with greater understanding of the relationship between diversity, inequality, and the effects of power were important consequences. For faculty teaching the course, these areas provided significant evidence of learning.

\section{Conclusions}

"I hated when people judged me as Hispanic because they would belittle Hispanics. Now when I stand up for myself, I am not angry any more because I know people need to be aware" (MexicanAmerican Female, Fall 2005).

This study explored student attitude change and the ability to transfer learning to real world contexts, an essential characteristic and aspect of learning from a Confluent Education (CE) framework. Teaching RCP required knowledge and awareness of the classroom context as a social environment, and a CE framework helped faculty to plan, structure, and interpret the process of the course in combination with the needs of students. Engaging students in multiple levels of learning also proved important as a structure in designing the RCP course. Students entered the course with personal beliefs and attitudes that were often in opposition to course materials and faculty knowledge, and the engaged high affective filters posed challenges in students' ability to understand and perceive the materials. Yet, by fostering Confluent Education principles that support "emergence as opposed to actively looking or finding" (Brown, J. R., 1996), students were able to increase their knowledge and awareness as active learners; thereby taking responsibility for their learning. This proved another critical aspect in the teaching of RCP, and may indicate a way to improve educational practice in the teaching of, for, and to issues of diversity and equity. Through the course structure and conscious guidance by faculty, students refined their notions of perspective-taking and reflective practice. Faculty were able to help students acknowledge multiple perspectives and value diversity within the communities of classrooms, and they presented opportunities for discovery of new perspectives and investigation of the real world. Students benefited from reading and thinking about the material, designing presentations, discussing ideas with peers, and listening to the perspectives of others that are sometimes vastly different than their own. Most significantly, the observation assignment helped them to connect what they were learning to the real world.

For faculty, teaching RCP is demanding, and those who continue to teach it will still need "breaks" from time to time to rejuvenate. As Asher (2007) concludes, faculty who teach courses such as this are "compelled to acknowledge that the cumulative effect of engaging narratives of racism and prejudice and encountering resistance to social transformation is exhausting" (p. 72). In fact, there always will remain some students in RCP courses who believe they already understand the issues and others who refuse to believe that the issues still exist. This makes teaching the course a stressful enterprise, and faculty often feel overwhelmed from dealing with these extremes. Yet, there is specific evidence important for faculty in this study: 38$55 \%$ of students who completed this course indicated an attitude change. Although this does not address the students who continued to maintain overtly negative or positive attitudes, it is important for educators who often feel discouraged about their efforts in teaching 
the topic. Meaningfully, this article highlights not only the way these courses are important, but also the ways that faculty are successful in the teaching of them. These data suggest that teachers of multicultural education and/or race culture and politics should not be disheartened by the difficulty of teaching this subject. And, there is evidence to suggest their work is having an important effect on attitude change and knowledge surrounding the topic within a substantial segment of the student population. Utilizing and actively practicing a CE framework helped faculty to anticipate these consequences.

Much like our students, faculty who participated in this study were provided with the opportunity to examine and reflect on "what is" and to learn new ways with "our eyes opened" to new perspectives about the work of teaching this course. It gave us the opportunity to focus on that significant percentage of "undecided" students and see the results of our efforts. As Boler and Greene, (1999) articulate, "a pedagogy of discomfort begins by inviting educators and students to engage in critical inquiry regarding values and cherished beliefs and to examine constructed self-images in relation to how one has learned to perceive others" (p. 177). The attention to feelings in the class, student led discussions, and opportunities for student investigation of the topics were critical aspects for teaching the RCP course that generated emotional responses and activated personal beliefs.

Beverly Daniel Tatum's (1997/2003) questions remain relevant for faculty who struggle with issues of race, culture and politics in countries around the globe. She asks, "What opportunities exist for building community, for encouraging dialogue across difference?" And, "How are students involved so that they are honing leadership skills in a diverse context?" (p. 216). Part of the answer to her questions may be in the teaching of Race, Class, and Politics from a Confluent Education framework that values cognitive learning, while addressing affective responses that may prohibit students from getting past personal beliefs and attitudes without conscious attention. However, it does not begin to address the more serious question Daniel Tatum alludes to: How do we work toward gaining a more diverse educational context with leadership from across marginalized groups as well as from those with the privilege of attending institutions such as the one in this study? Answering this question is more difficult, but may benefit from courses that address the divide between the theory and public opinion, and the mismatch between what is studied and what is believed.

\section{Acknowledgements}

The author wishes to thank all who contributed to this study in substantial ways including Professors Karen Munoz-Christian and Aaron Rodriguez. Most significantly, thank you to all the students whose contributions and willingness to examine their perspectives, beliefs and attitudes with honesty and insight provided access to a complex process normally hidden.

\section{References}

Asher, N. (2007). Made in the (multicultural) U.S.A.: unpacking tensions of race, culture, gender, and sexuality in education. Educational Researcher, 36(2), 65-73.

Banks, J. (2009). The Routledge international companion to multicultural education. New York: Routledge.

Boler, M., \& Greene, M. (1999). Feeling power: Emotions and education. New York: Routledge.

Brown, G. (1972/1990). Human teaching for human learning. Highland, NY: The Gestalt Journal.

Brown, J. H. (1996). Confluence in education: Integrating consciousness for human change. Greenwich, CT: JAI Press.

Brown, L. (2006). The development of emotional competency in holistic transformational education. Presentation to the Indigenous Peoples of the Pacific
SIG, annual conference of the American Educational Research Association, San Francisco.

Brown, J. R. (1996). The I in science: Training to utilize subjectivity in research. Boston: Scandinavian University Press.

Bruner, J. S. (1996). The culture of education. Cambridge, MA: Harvard University Press.

Castillo, G. A. (1978). Confluent education Manitoba style. Winnepeg, can: confluent education program, Frontier school division.

Cole, M., John-Steiner, V., Scribner, S., \& Souberman, E. (1978). Mind in society: The development of higher psychological processes. Cambridge: Harvard University Press.

Daniel Tatum, B. (2003). “Why are all the Black kids sitting together in the cafeteria?" And other conversations about race. New York: Basic Books.

D'Emidio-Caston, M. (1999). Confluent education: a pedagogy to bridge cultural boundaries. In J. H. Brown (Ed.), Advances in Confluent Education, Vol. 2 (pp. 49-71) NY: JAI Press.

Elliot, J., and Elliot Eyes Production, Inc. (2001). The angry eye: with Jane Elliot Pennsylvania Production, Inc. (Film).

Freire, P. (1970/2000). Pedagogy of the oppressed. New York: Continuum.

Gardner, H. (1983). Frames of mind: The theory of multiple intelligences. NY: Basic Books.

Gergen, K. J. (1999). An invitation to social construction. Thousand Oaks, CA: Sage Pub.

Grimes, R. L. (2000). This may be a feud, but it is not a war: an electronic interdisciplinary dialogue. In Lee Irwin (Ed.), Native American spirituality: A critica reader (pp. 78-96). Lincoln: University of Nebraska Press.

Gurin, P., \& Nagda, B. A. (Jan/Feb, 2006). Getting to the what, how, and why of diversity on campus. Educational Researcher, 35(1), 20-24.

Hackbarth, S. (1996). Confluent education: an analysis from the perspective of Merleau-Ponty's philosophy. In J. H. Brown (Ed.), Advances in confluent education. Greenwich, CT: JAI Press.

Koppelman, K. L., \& Goodhart, R. L. (2005). A human relations attitude inventory. In understanding human differences: Multicultural education for a diverse America. 350-353.

Ladson-Billings, G. (2004). Landing on the wrong note: the price we paid for Brown Educational Researcher, 33(7), 3-13.

Mantsios, G. (2004). Class in America-2003. In Paula S. Rothenberg (Ed.), Race, class, and gender in the United States (pp. 193-207). New York: Worth Publishers.

Marshall, C., \& Rossman, G. B. (1989). Designing qualitative research. Newbury Park, CA: Sage Pub.

Martin, K. J. (April 1998). Qualitative research and confluent education: a method for the study of differences and the expression of diversity. Paper presentation, American educational research Association Annual meeting. San Diego, CA.

Martin, K. J., Chrispeels, J. H., \& D’Emidio-Caston, M. (1998). Exploring the use of problem-based learning for developing future administrators collaborative leadership skills. Journal of School Leadership, 8(5), 470-500.

Miles, M. B., \& Huberman, A. M. (1994). Qualitative data analysis: An expanded sourcebook. Thousand Oaks, CA: Sage Publications.

Miner, H. (1996). Body ritual of the Nacirema. In A. C. Lehmann, \& J. E. Myers (Eds.), Magic, witchcraft, and religion (4th ed.). (pp. 71-74) Mountain View, CA: Mayfield Pub.

Moses, M. S., \& Marin, P. (Jan/Feb 2006). Informing the debate on race-conscious education policy. Educational Researcher, 35(1), 3-5.

Osterman, K. F., \& Kottkamp, R. (1993). Reflective practice for educators. Newberry Park, CA: Corwin Press.

Parenti, M. (2006). Mass media: for the many by the few. In P. S. Rothenberg (Ed.), Beyond borders: Thinking critically about global issues (pp. 60-72). New York Worth Publishers.

Rothenberg, P. (2004). Race, class, and gender in the United States. New York: Worth Pub.

Senge, P. (1999). The dance of change: The challenge of sustaining momentum in learning organizations. New York: Currency Doubleday.

Shapiro, S. B. (1997). The UCSB confluent education program: its essence and demise. Journal of Humanistic Psychology,, 37(3), 79-104.

Shapiro, S. B. (1998). The place of confluent education in the human potential movement: A historical perspective. NY: University Press of America.

Shor, I., \& Pari, C. (Eds.). (2000). Education is politics: Critical teaching across differences, postsecondary. Portsmouth, $\mathrm{NH}$ : Boynton/Cook.

Stringer, E. (1993). Socially responsive educational research: linking theory and practice. In D. Flinders, \& G. Mills (Eds.), Theory and concepts in qualitative research (pp. 141-162). New York: Faculty College Press.

Suzuki, S., Fishman, D. K., \& Pušina, A. (2007). Learning in and out of classrooms: possibilities, prospects, comparative perspectives. Paper presentation at the world Council of comparative education societies (WCCES). Sarajevo University, Bosna/Hercegovina.

Van Maanen, J. (Ed.). (1998). Qualitative studies of organizations. Thousand Oaks, CA: Sage Publications.

Yun, J. T., \& Moreno, J. F. (2006). College access, K-12 concentrated disadvantage, and the next 25 years of educational research. Educational Researcher, 35(1), $12-19$. 